\title{
ASSOCIATION OF ADVERSE PERINATAL OUTCOMES WITH INCREASING AGE IN TWIN PREGNANCIES AT A TERTIARY CARE HOSPITAL.
}

\author{
DR. RUKHSAR SHAHEEN \\ MBBS, \\ NISHTAR HOSPITAL, MULTAN, PAKISTAN.
}

DR. MUHAMMAD MUDASIR HUSNAIN

MBBS,

NISHTAR HOSPITAL, MULTAN, PAKISTAN.

DR. MUHAMMAD SHEHZAD KHAN KHATTAK

MBBS,

NISHTAR HOSPITAL, MULTAN, PAKISTAN.

\begin{abstract}
;
Background; Twin pregnancies in low- and middle-income countries (LMICs) pose a high risk to mothers and newborns due to inherent biological risks and scarcity of health resources which translate into insufficient care during pregnancy and delivery. Due to inherent biological factors, twin pregnancies have increased rates of obstetric and perinatal complications such as preeclampsia, post-partum haemorrhage and preterm birth, which are known risk factors for maternal and perinatal mortality. Objective; To determine the frequency of adverse fetomaternal outcome in twin pregnancy in women of advanced age. Material and methods: A total of 181 patients with dichorionic diamniotic twin pregnancy on ultrasound having gestational age more than 24 weeks were taken in this cross-sectional study. Demographic information of patients (name, age, weight) was taken. Informed consent was taken from each patient, ensuring confidentiality and fact that there is no risk involved to the patient while taking part in this study. An obstetrical ultrasonography was done to confirm twin pregnancy. Blood samples were taken from all patients for assessment of anemia. Patients were followed up until pregnancy outcome. Results; Mean age of these study cases was noted to be $34.35 \pm 2.41$ years. Mean gestational age of our study cases was $34.67 \pm 2.25$ weeks. Mean BMI of our study cases was noted to be $22.45 \pm 1.67 \mathrm{~kg} / \mathrm{m}^{2}$ (with minimum BMI was $19.4 \mathrm{~kg} / \mathrm{m}^{2}$ and maximum BMI was $\left.32 \mathrm{~kg} / \mathrm{m}^{2}\right)$ and obesity was present in $27(14.9 \%)$ of our study cases. Of these 181 study cases, $126(69.6 \%)$ delivered vaginally while $55(30.4 \%)$ had to undergo cesarean section delivery. Mean hemoglobin level was noted to $8.67 \pm 1.40 \mathrm{~g} / \mathrm{dl}$ while anemia was seen in 126 $(69.6 \%)$ of these study cases. Preterm labor was observed in $144(79.6 \%)$, abruptio placentae in $19(10.5 \%)$ and low birth weight in 123 (68\%) of our study cases.
\end{abstract}


Conclusion; Twin pregnancy is associated with high risk of perinatal and pregnancy outcomes. There was higher frequency of anemia, cesarean section deliveries, preterm births and low birth weight babies in our study. There is a need for specialised prenatal care to reduce complications and adverse outcome in multiple pregnancies, and the need for ongoing social and medical care beyond the prenatal and perinatal periods to improve perinatal outcomes in these patients.

Keywords; Preterm labor, anemia, twin pregnancy.

DOI: $10.7176 / \mathrm{JMPB} / 58-04$

Publication date: August $31^{\text {st }} 2019$

\section{Introduction:}

Multiple gestation currently account for $3 \%$ of all pregnancies. ${ }^{1}$ Compared to singleton pregnancies the perinatal mortality, morbidity and long term neuro-developmental disability are increased $5-10$ fold in twin pregnancies. $^{2}$

Although twins occur in approximately one of 80 pregnancies, corresponding to $2.6 \%$ of all newborns, they account for $12.2 \%$ of preterm births and $15.4 \%$ of neonatal deaths. ${ }^{3}$ The main causes of adverse neonatal outcomes in multiple pregnancies are related to prematurity, fetal growth restriction and low birth weight. ${ }^{4}$ In addition, these pregnancies are prone to complications inherent to twinning, such as acardiac fetus, conjoined twins and twin-twin transfusion syndrome. In addition, the risk of congenital anomalies is about 1.7 times higher than among singleton pregnancies and is more significant in monozygotic pregnancies. ${ }^{4,5}$

Preterm birth is observed in approximately 54\% of all twin pregnancies, half of these births have a iatrogenic origin and are related to maternal or fetal complication while the other half consists of cases of spontaneous premature labor or premature membrane rupture. ${ }^{3}$ The average birth weight is $2367 \mathrm{~g}$ and about $52 \%$ of the newborns weigh less than $2500 \mathrm{~g}$. The risk of growth restriction is three times higher than in singleton pregnancies. ${ }^{6,7}$

When analyzed according to chorionicity, monochorionic pregnancies present a two to three times higher risk than dichorionic pregnancies. ${ }^{89}$ The risk factors for multiple gestation births have been well documented. ${ }^{10}$ These include family history of twins, heredity, advanced age, serum oestradiol concentration, race, and use of fertility treatment. as compared to women with singleton gestations. ${ }^{11}$ In addition, multiple gestations are associated with increased cost to families and health care system. ${ }^{12}$ All these factors are the reasons why multiple pregnancies remain a major public health problem as compared to singleton pregnancies, particularly in sub continent, given the high maternal mortality rate in the region. Rizwan $\mathrm{N}$ and her associates has found in a recent study that $84 \%$ patients presented with preterm labour, anaemia was found in $65.6 \%$, Abruptio placentae occurred in $6.2 \%$ of cases and low birth weight was $32.8 \%$ in women of advanced age with twin pregnancy. ${ }^{13}$ In another recent study has found that $76.6 \%$ had preterm deliveries, anaemia was found in $50 \%, 53 \%$ LSCS of cases and low birth weight was $57 \%$ in women of advanced age with twin pregnancy. ${ }^{14}$

\section{Material and methods:}

A total of 181 patients with dichorionic diamniotic twin pregnancy on ultrasound having gestational age more than 24 weeks were taken in this cross-sectional study. While primigravidas, grand-multigravidas $(>5)$, diabetic, hypertensive and patients having renal disorders were excluded. This study was conducted at Department of Obstetrics and Gynecology, Nishtar Hospital Multan, Pakistan. Demographic information of patients (name, age, weight) was taken. Informed consent was taken from each patient, ensuring confidentiality and fact that there is no risk involved to the patient while taking part in this study. An obstetrical ultrasonography was done to confirm twin pregnancy. Blood samples were taken from all patients for assessment of anemia. Patients were followed up until pregnancy outcome. Abruptio placentae and preterm labour were managed as per protocol. Maternal outcomes were noted while after delivery fetal outcome in shape of Low Birth Weight were recorded. Data was analyzed with statistical analysis program (SPSS version15).

\section{Results;}

In this study, a total 181 women with twin pregnancy were registered. Mean age of these study cases was noted to be $34.35 \pm 2.41$ years (with minimum age was 31 years while maximum age was 40 years). Our study results have indicated that majority of our study cases i.e. $118(65.2 \%)$ had age ranging from $30-35$ years. Mean gestational age of our study cases was $34.67 \pm 2.25$ weeks (with lowest gestational age was 28 weeks while maximum gestational age was 38 weeks). Majority of our study cases i.e. $126(69.6 \%)$ had gestational age up to 35 weeks. Mean BMI of our study cases was noted to be $22.45 \pm 1.67 \mathrm{~kg} / \mathrm{m}^{2}$ (with minimum BMI was 19.4 
$\mathrm{kg} / \mathrm{m}^{2}$ and maximum BMI was $32 \mathrm{~kg} / \mathrm{m}^{2}$ ) and obesity was present in $27(14.9 \%)$ of our study cases. Of these 181 study cases, $126(69.6 \%)$ delivered vaginally while $55(30.4 \%)$ had to undergo cesarean section delivery. Mean hemoglobin level was noted to $8.67 \pm 1.40 \mathrm{~g} / \mathrm{dl}$ (with minimum Hb level was $7 \mathrm{~g} / \mathrm{dl}$ while maximum Hb level was $11.5 \mathrm{~g} / \mathrm{dl}$ ) while anemia was seen in $126(69.6 \%)$ of these study cases. Preterm labor was observed in 144 (79.6\%), abruptio placentae in $19(10.5 \%)$ and low birth weight in $123(68 \%)$ of our study cases.

\section{Discussion;}

Twin pregnancy results from one of two distinct biological processes. The more common process is fertilisation of more than one ovum following multiple ovulation. Here the offspring may be of the same gender or not, are genetically no more similar than siblings, and have separate placental circulations and gestational sacs (dizygotic, diamniotic, dichorionic). In this study, a total 181 women with twin pregnancy were registered. Mean age of these study cases was noted to be $34.35 \pm 2.41$ years (with minimum age was 31 years while maximum age was 40 years). Our study results have indicated that majority of our study cases i.e. $118(65.2 \%)$ had age ranging from $30-35$ years. Rizwan et al ${ }^{13}$ reported similar results. Schuit et al ${ }^{15} 31.6 \pm 5.6$ years mean age which is close to our study results.

Mean gestational age of our study cases was $34.67 \pm 2.25$ weeks (with lowest gestational age was 28 weeks while maximum gestational age was 38 weeks). Majority of our study cases i.e. $126(69.6 \%)$ had gestational age up to 35 weeks. Rizwan et al ${ }^{13}$ and Bangal et al ${ }^{16}$ reported similar patterns. Bhavana et al ${ }^{17}$ reported 35.4 week mean gestational age showing similar results like ours. Mean BMI of our study cases was noted to be $22.45 \pm$ $1.67 \mathrm{~kg} / \mathrm{m}^{2}$ (with minimum BMI was $19.4 \mathrm{~kg} / \mathrm{m}^{2}$ and maximum BMI was $32 \mathrm{~kg} / \mathrm{m}^{2}$ ) and obesity was present in $27(14.9 \%)$ of our study cases. Schuit et al ${ }^{15}$ reported $25.7 \pm 6.3 \mathrm{~kg} / \mathrm{m}^{2}$ these findings are similar to our study results considering our Asian population. Sultana et al ${ }^{18}$ reported similar results. Of these 181 study cases, 126 $(69.6 \%)$ delivered vaginally while $55(30.4 \%)$ had to undergo cesarean section delivery. Bangal et al ${ }^{16}$ reported $33 \%$ cesarean sectional deliveries associated with twin pregnancies these findings are similar to that of our study results.

Mean hemoglobin level was noted to $8.67 \pm 1.40 \mathrm{~g} / \mathrm{dl}$ (with minimum $\mathrm{Hb}$ level was $7 \mathrm{~g} / \mathrm{dl}$ while maximum $\mathrm{Hb}$ level was $11.5 \mathrm{~g} / \mathrm{dl}$ ) while anemia was seen in $126(69.6 \%)$ of these study cases. Chowdhury et al ${ }^{19}$ reported $35.8 \%$ anemia in ladies with twin pregnancy which is quite lower than our study findings. Bangal et al 16 reported $66 \%$ anemia, which is similar to that of our study results. Rizwan et al ${ }^{13}$ reported $65.6 \%$ which are again same as that of our study findings. Bhavana et al ${ }^{17}$ reported $50 \%$ anemia which is close to our findings. Preterm labor was observed in $144(79.6 \%)$, Gardnder et al ${ }^{3}$ reported $54 \%$ preterm birth as major perinatal complication which is in compliance with our study results. Bangal et al ${ }^{16}$ reported $84 \%$ preterm labor which is same as that of our study results. Rizwan et al ${ }^{13}$ also reported $84 \%$ preterm births which is close to our study results. Bhavana et al ${ }^{17}$ reported $76.6 \%$ preterm deliveries in such cases which is in compliance with our study results. Sultana et al ${ }^{18}$ reported $64 \%$ preterm births which is similar to our findings. Abruptio placentae was seen in $19(10.5 \%)$ of our study cases. Gardner et al ${ }^{3}$ reported $9 \%$ placental abruption which is close to our study results. Rizwan et $\mathrm{al}^{13}$ reported $6.2 \%$ placental abruption which is similar to that of our study results. Low birth weight in 123 (68\%) of our study cases. Rizwan et al ${ }^{13} 78 \%$ low birth weight which is similar to that of our study results. Bhavana et al ${ }^{17}$ reported $57 \%$ low birth weight babies which is close to our findings.

\section{Conclusion;}

Twin pregnancy is associated with high risk of perinatal and pregnancy outcomes. There was higher frequency of anemia, cesarean section deliveries, preterm births and low birth weight babies in our study. There is a need for specialized prenatal care to reduce complications and adverse outcome in multiple pregnancies, and the need for ongoing social and medical care beyond the prenatal and perinatal periods to improve perinatal outcomes in these patients.

\section{References:}

1. Rather SY, Habib R, Sharma P. Studying pregnancy outcome in twin gestation in developing world. IOSR J Dent Med Sci. 2014;13(5):62-5. 
2. Schuit E, Stock S, Rode L, Rouse DJ, Lim AC, Norman JE, et al. Effectiveness of progestogens to improve perinatal outcome in twin pregnancies: an individual participant data meta-analysis. BJOG. 2015;122:27-37.

3. Gardner MO, Goldenberg RL, Cliver SP, Tucker JM, Nelson KG, Copper RL. The origin and outcome of preterm twin pregnancies. Obstet Gynecol. 1995;85(4):553-7.

4. Glinianaia SV, Rankin J, Renwick M. Time trends in twin perinatal mortality in northern England, 1982-94. Northern Region Perinatal Mortality Survey Steering Group. Twin Res. 1998;1(4):189-95.

5. Brizot M, Fujita M, Reis N, Banduki J, Schultz R, Miyadahira S, et al. Malformações fetais em gestação múltipla. Rev Bras Ginecol Obstet. 2000;22(8):511-7.

6. Alexander GR, Salihu HM. Perinatal outcomes of singleton and multiple births in the United States, 1995-98. In: Blickstein I, Keith LG, editors. Multiple Pregnancy: epidemiology, gestation \& perinatal outcome. $2^{\text {nd }}$ ed. Andover: Thompson Publishing Services; 2005. pp. 3-10.

7. Umstad MP, Lancaster PAL. Multiple births in Australia. In: Blickstein I, Keith LG, editors. Multiple pregnancy: epidemiology, gestation \& perinatal outcome. $2^{\text {nd }}$ ed. Andover: Thomson Publishing Services; 2005. pp. 26-32.

8. Hack KE, Derks JB, Elias SG, Franx A, Roos EJ, Voerman SK, et al. Increased perinatal mortality and morbidity in monochorionic versus dichorionic twin pregnancies: clinical implications of a large Dutch cohort study. Br J Obstet Gynecol. 2008;115(1):58-67.

9. Loos R, Derom C, Vlietinck R, Derom R. The East Flanders prospective twin survey (Belgium): a population-based register. Twin Res. 1998;1(4):167-75.

10. Dickey RP, Taylor SN, Lu PY, Sartor BM, Rye PH, Pyrzak R. Relationship of follicle numbers and estradiol levels to multiple implantation in 3608 intrauterine insemination cycles. Fertil Steril. 2001;75(1):69-78.

11. Garg P, Abdel-Latif ME, Bolisetty S, Bajuk B, Vincent T, Lui K. Perinatal characteristics and outcome of preterm singleton, twin and triplet infants in NSW and the ACT, Australia (1994-2005). Arch Dis Child. 2010;95(1):F20-4.

12. Lukassen HGM, Schönbeck Y, Adang EMM, Braat DDM, Zielhuis GA, Kremer JAM. Cost analysis of singleton versus twin pregnancies after in vitro fertilization. Fertil Steril. 2004;81(5):1240-46.

13. Rizwan N, Abbasi RM, Mughal R. Maternal morbidity and perinatal outcome with twin pregnancy. J Ayub Med Coll Abbottabad. 2010 Apr-Jun;22(2):105-7.

14. Bhavana S, Shivanna S, Gopal N. A study on fetomaternal outcome in twin gestation in a tertiary rural health centre. Int J Adv Res Med Sci. 2014 Nov;1(1):15-21.

15. Schuit $E^{1}$, Stock S, Rode L, Rouse DJ, Lim AC, Norman JE, et al. Effectiveness of progestogens to improve perinatal outcome in twin pregnancies: an individual participant data meta-analysis. BJOG. 2015 Jan;122(1):27-37.

16. Bangal VB, Patel SM, Khairnar DN. Study of maternal and fetal outcome in twin gestation at Tertiary care teaching hospital. Int J Biomed Adv Res. 2012;3(10):758-62.

17. Bhavana $\mathrm{S}$, Shivana $\mathrm{S}$, Gopal N. A study on fetomaternal outcome in twin gestation in a tertiary rural health centre. Int J Adv Res Med Sci. 2014;1(1):15-21.

18. Sultana M, Khatun S, Ara R, Saha AK, AKhter P, Shah AS. Maternal and perinatal outcome of twin pregnancy at tertiary care hospital. Ibrahim Card Med J. 2011;1(2):35-39.

19. Chowdhury S, Hussain MA. Maternal complications in twin pregnancies. Mymensingh Med J. 2011 Jan;20(1):83-7. 